\title{
Review
}

\section{From receptor to transporter: insulin signalling to glucose transport}

\author{
G.D. Holman ${ }^{1}$, M. K asuga ${ }^{2}$ \\ ${ }^{1}$ The School of Biology and Biochemistry, The University of Bath, Bath, UK \\ ${ }^{2}$ The Second Department of Internal Medicine, Kobe University School of Medicine, Kobe, Japan
}

\section{Introduction}

In the early 1980s two important discoveries revealed the beginning and end of a cascade of reactions that link the interaction of insulin with its receptor and the stimulation of the uptake of glucose into mammalian cells. First, Kasuga et al. [1,2] discovered that the occupied insulin receptor is a tyrosine kinase leading to both tyrosine autophosphorylation of the receptor $\beta$-subunit and of cellular substrates. Second, Cushman and Wardzala [3] and Suzuki and Kono [4] discovered that glucose transporters are mainly resident in intracellular membrane vesicles in the absence of insulin and that insulin stimulation leads to an increase in the recruitment of these transporters to the plasma membrane. This translocation accounts for the increased rates of glucose transport into the stimulated cells. Details have emerged concerning both the beginning and end of the cascade and gradually the intermediate events in signalling and glucose transporter recruitment are being elucidated.

The success in identifying these intermediate steps has not been as rapid as that which has led to the elucidation of the intermediate signalling events involved in stimulation of cell growth and mitosis. In this cascade, a key switch in signalling occurs between tyrosine kinase activation and serine/threonine kinase activation. The switch occurs through the G-protein

Corresponding author: Professor G. D. Holman, The School of Biology and Biochemistry, The University of Bath, Bath BA2 7AY, UK

A bbreviations: IRS, Insulin receptor substrate; PI, phosphatidylinositol; GLUT, glucose transporter isoform; PH, pleckstrin homology; PTB, phosphotyrosine binding domain; Map, mitogen activated protein; M6PR, mannose 6-phosphate receptor; NSF, N-ethylmaleimide sensitive fusion; SNAP, soluble NSF attachment proteins; PKC, protein kinase C; PKB, protein kinase B; PDGF, platelet derived growth factor; EGF, epidermal growth factor.
Ras which activates downstream Raf and mitogen activated protein (Map) kinases [5-8]. Such a switch has not been demonstrated for the reactions leading to stimulation of glucose transport and, as we describe below, there is evidence that the Map kinase pathway is not involved in the activation process.

The divergence of mitotic stimulation and metabolic stimulation (via increased glucose transport) is clearly necessary in the insulin-target tissues of muscle and fat where there is a requirement that increased metabolic flux is acutely regulated over short timescales without a concomitant stimulation of cell growth and division. The extent to which these two signalling pathways diverge has also been difficult to dissect as studies of cell culture models and cell free systems have suggested that there is the potential for cross-talk between these two pathways. Such crosstalk may be less significant in cells that are specialised to perform discrete functions. Given the complexity of the possible interactions between signalling intermediates, the mapping of a direct cascade leading to increased glucose transport is at present incomplete. Therefore, this review describes some of the advances that have been made in the search for intermediates which lead to glucose transporter translocation and speculates on possible mechanisms and missing links that may be involved in the complete signalling pathway.

\section{Insulin receptor mutants altering glucose transport}

The cascades leading to stimulated glucose transport and activation of the Ras/Map kinase pathway (Fig. 1) begin at the insulin receptor, an $\alpha 2 \beta 2$ tetramer [9]. The $\alpha$-subunit is located entirely at the extracellular face of the plasma membrane and contains the insulin binding site. The $\beta$-subunit is a transmembrane peptide. The $\beta$-subunit possesses tyrosine-specific 


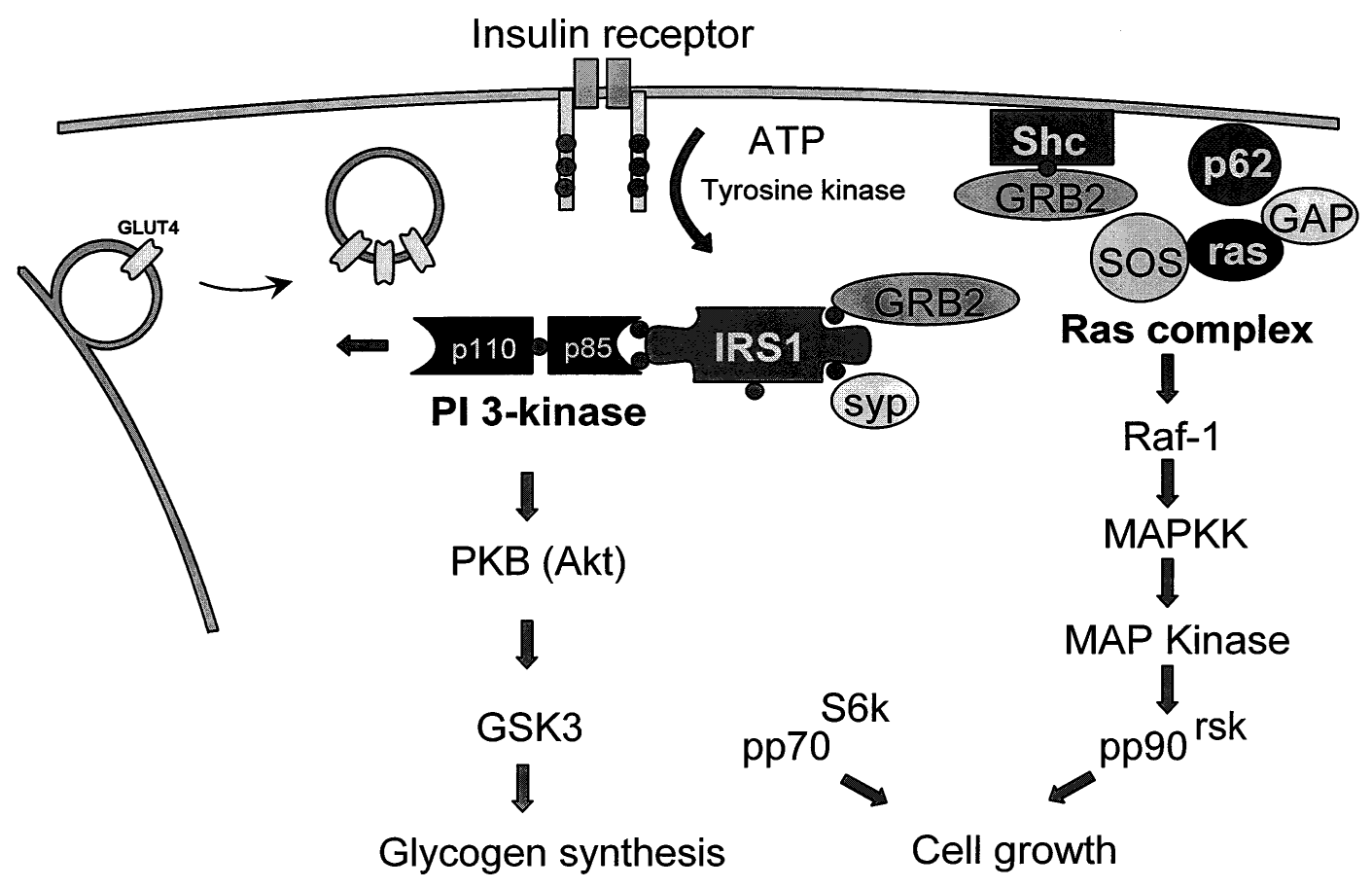

Fig. 1. Insulin signalling pathways. Much of insulin signalling involves cascades of direct protein-protein interaction that is initiated at the level of the insulin receptor. The tyrosine kinase activity of the insulin receptor leads to the tyrosine phosphorylation of IRS1, IRS2 and Shc. The phosphotyrosine residues in these proteins $(\bigcirc)$ interact via $\mathrm{SH} 2$ domains with adapter subunits of key signalling intermediates. These include Grb2-SOS, Syp and PI 3-kinase. The Grb2-SOS system leads to activation of the Map kinase pathway via Ras activation, the tyrosine phosphatase Syp modulates the Map kinase and possibly other effector pathways while the PI 3-kinase pathway leads to stimulation of glucose transport, glycogen synthesis and membrane ruffling

protein kinase activity in the intracellular domain. Insulin binding to the $\alpha$-subunit leads to the phosphorylation of the $\beta$-subunit of the receptor on tyrosine residues $[1,2]$. This autophosphorylation process is associated with increased tyrosine kinase activity toward intracellular substrates.

Surprisingly, occupation of the insulin receptor by insulin is not essential for insulin receptor signalling. Anti-insulin receptor antibodies can activate glucose transport. This probably occurs as the result of receptor crosslinking which leads to activated tyrosine kinase activity [10]. The tyrosine kinase activity is essential for subsequent signalling. Human insulin receptors mutated in the ATP-binding site of the tyrosine kinase domain (at lysine 1018) fail to mediate postreceptor effects of insulin in CHO cells $[11,12]$ and NIH 3 T3 fibroblasts [13]. Mutation in this domain leads to both defective activation of the Ras/ Map kinase pathway and defective stimulation of glucose transport $[12,13]$. The requirement for an active receptor tyrosine kinase as a prerequisite for GLUT4 translocation has also recently been demonstrated in a rat adipocyte transfection system. Overexpression of human insulin receptors raises basal levels of GLUT4 expression but receptors with a Met1153-Ile mutation (lacking tyrosine kinase activity) fail to mediate this enhanced basal translocation [14].

The receptor C-terminal tyrosines 1316 and 1322 are not essential for signalling to glucose transport but may be important for activation of the Ras/Map kinase pathway; the insulin dose-response curve is shifted to the right by 5-10-fold [15]. C-terminally truncated mutants in which the C-terminal tyrosines are deleted show defective autophosphorylation and a $46 \%$ reduction in internalisation but normal phosphorylation of intracellular substrates such as insulin-receptor substrate-1 (IRS1) and Shc (Fig. 1). The dose-response curve for activation of glucose transport is variably altered [16-18] but the maximum insulin stimulation appears to be unaltered by C-terminal truncation [16]. Taken together these data suggest that in signalling to downstream processes, the C-terminal autophosphorylation of the insulin receptor may be less important than the tyrosine-kinase-mediated phosphorylation of intracellular substrates. Further evidence for a divergence of signalling at the level of the insulin receptor comes from studies of a Tyr960-Ala mutation in the juxtamembrane domain. This mutant shows severely impaired tyrosine phosphorylation of IRS1 and Shc but only moderately impaired activation of Ras $[19,12]$. The downstream activation of glucose transport is lost suggesting that this process is more associated with IRS1 and Shc than with activation of Ras [12]. 
3. Tyrosine phosphorylation and dephosphorylation of insulin receptor substrates and their involvement in glucose transport stimulation

IRS1, IRS2 and Shc are all phosphorylated in response to tyrosine phosphorylation by the insulin receptor (Fig.1). cDNA cloning has revealed that IRS1 contains 22 potential tyrosine phosphorylation sites that serve as specific recognition sites for cellular substrates bearing SH2 domains [20, 21]. A pleckstrin homology $(\mathrm{PH})$ domain is important for association of IRS1 with the insulin receptor [22]. IRS1 also contains a phosphotyrosine binding (PTB) domain which recognises the NPXY ${ }^{960}$ sequence of the insulin receptor. Mutagenesis has suggested that this region is important for IRS1 phosphorylation and activation of glucose transport (Section 2). The recognition of IRS1 is dependent on the tyrosine phosphorylation of Tyr960 [23].

Tyrosines 460, 608,939 and 987 in IRS1 are known to be bound strongly by the SH2 domains of the $\alpha$ p85 subunit of PI 3-kinase. IRS1 is also phosphorylated by the insulin-like growth factor (IGF1) receptor tyrosine kinase activity [24] but is not phosphorylated in response to platelet derived growth factor (PDGF) or epidermal growth factor (EGF). The latter two growth factors do not acutely stimulate glucose transport in its target cells under normal physiological conditions but effects have been observed in cell systems over-expressing their receptors. Glucose transport activity in IRS1-knockout mice is increased in response to insulin but the maximal stimulation is reduced in comparison with control mice $[25,26]$. A complicating factor in interpreting these data is the presence of IRS2 in the IRS1-knockout mice [27]. IRS2 can also couple to $\alpha$-p85 and may replace the missing signalling intermediate. Whether IRS2 plays a major role in normal stimulation of glucose transport in fat and muscle has not yet been fully evaluated. In addition, it is possible that other phosphotyrosine substrates of the insulin receptor kinase activity are up-regulated to compensate for the decrease in IRS1 in these mice. Other evidence that IRS1 is utilised in initiating GLUT4 translocation has been obtained by antisense ablation of this molecule in rat adipocytes. The ablation results in a shift in the insulin dose response curve to the right (indicating a reduction in insulin sensitivity) but the maximal level of stimulation of transport activity is unaltered [28]. At present it is unclear whether IRS1 alone is responsible for downstream stimulation of glucose transport particularly as microinjection of anti-IRS1 antibodies, PTB domain constructs and NPX-phosphotyrosine peptides into 3T3-L1 adipocytes reduces IRS1 interaction with phosphatidylinositol (PI) 3-kinase but has no effect upon insulin-induced translocation of GLUT4. However, these materials inhibit other aspects of insulin action including effects on membrane ruffling and mitogenesis [29].
Shc is also a tyrosine phosphorylated substrate of the insulin receptor. A PTB domain in Shc interacts with Tyr960 in the juxtamembrane region of the receptor [12]. Phosphorylated Shc binds to the SH2 domains of Grb2 and this coupling activates the Map kinase pathway following Grb2 /SOS interaction (Fig.1). As discussed above, Shc activation alone is insufficient to activate the Map kinase pathway as the Tyr960 mutation of the insulin receptor leads to normal Shc phosphorylation but impaired signalling through Ras/Map kinase. Since the Ras/ Map kinase pathway does not appear to be involved in glucose transport stimulation (see Section 6b), it seems unlikely that Shc is involved either. However, it cannot be ruled out that phosphorylated Shc may couple to pathways other than the Map kinase pathway and that these do lead to glucose transport stimulation.

Syp (SH-PTP2) binds to IRS1 through SH2 domains and this leads to increases in its tyrosine phosphatase activity [30]. Expression of a dominant-negative mutant of Syp in CHO-IR cells reveals that Syp is an upstream regulator of the Ras/MAP kinase pathway but not of PI 3-kinase [31], suggesting that Syp is not involved in insulin-stimulated glucose transport. Microinjection of Syp SH2 domains or antibodies to Syp into 3T3-L1 cells blocks insulin-induced mitogenesis but not insulin-stimulated GLUT4 translocation. Over longer incubations, increased expression of GLUT1 is observed and this leads to an increase in glucose transport activity [32].

\section{Role of PI 3-kinase as an intermediate leading to glucose transport stimulation}

A family of PI 3-kinases phosphorylate the inositol ring at the D-3 position to give PI 3-phosphate from PI, PI 4,5-bisphosphate from PI 4-phosphate and PI 3,4,5-trisphosphate from PI 4,5-bisphosphate [33, 34]. The first characterised mammalian PI 3-kinase was shown to be a heterodimer consisting of $85 \mathrm{kDa}$ $(\alpha-p 85)$ and $110 \mathrm{kDa}(\mathrm{p} 110)$ subunits. Cloning of these subunits has revealed that the $\alpha$-p85 is an adapter subunit containing two $\mathrm{SH} 2$ domains and one SH3 domain [35-37] while the p110 subunit has catalytic activity $[38,39]$. It is the presence of the SH2 domains and their demonstrated ability to bind phosphotyrosine that has led this form of PI 3-kinase being strongly implicated in insulin action in target tissues.

In 1990, experiments by Endemann et al. [40] and Ruderman et al. [41]demonstrated that insulin treatment increases PI 3-kinase activity in phosphotyrosine immunoprecipitates. Insulin, at concentrations as low as $0.3 \mathrm{nmol} / 1$, stimulates the accumulation of PI 3,4,5trisphosphate by about 10 times basal levels within $5 \mathrm{~min}$. Therefore, these effects occur at physiological 
concentrations of insulin and within the known timescale of insulin action on glucose transport and its cellular metabolism. Initially this increased activity was considered to be due to the tyrosine-phosphorylation of PI 3-kinase or the association of PI 3-kinase with the tyrosine-phosphorylated insulin receptor. The $\mathrm{C}$ terminal tail of the insulin receptor including the phosphotyrosine motif $\mathrm{Y}^{1132} \mathrm{THM}$ can bind PI 3-kinase [42]. However, only a small (1-3\%) amount of the PI 3-kinase activity which can be precipitated with anti-phosphotyrosine antibody is co-precipitatable with anti-insulin receptor antibodies [43]. Instead, tyrosine-phosphorylation of YMXM motifs in IRS1 with subsequent binding and activation of $\alpha$ p85 has been demonstrated to provide a means of coupling the insulin receptor tyrosine kinase activity with the activation of intracellular PI 3-kinase activity $[30,44,45]$.

To explore the role of PI 3-kinase activity in insulin action a strategy has been developed to disrupt complex formation between PI 3-kinase and IRS1 (or possibly other tyrosine phosphorylated substrates of the receptor that could couple to the heterodimeric form of PI 3-kinase). Hara et al. [46, 47] developed a mutant $\Delta \mathrm{p} 85$ which lacks a binding site for the catalytic p110 subunit [48]. This construct has been stably introduced into $\mathrm{CHO}$ cells overexpressing the insulin receptor. In this cell line, although activation of insulin receptor kinase and tyrosine-phosphorylation of IRS1 are unaffected, the insulin-induced increase in PI 3-kinase activity immunoprecipitated with antiphosphotyrosine is greatly attenuated. Furthermore in this cell line, insulin stimulation of glucose uptake is markedly impaired, in contrast to the insulin-stimulation of Ras activation which is not. These results were the first to suggest that the $\alpha$-p85 coupled PI 3kinase is required for insulin-dependent glucose uptake $[46,47]$. Subsequently it has been demonstrated that microinjected $\Delta \mathrm{p} 85$ inhibits the translocation of GLUT4 in 3T3-L1 cells as assessed using a plasma membrane lawn assay in which GLUT4 is immunologically detected [49]. Recently, the same result has been confirmed following introduction of $\Delta \mathrm{p} 85$ into 3T3-L1 cells using an adenovirus vector (Sakaue et al., manuscript in preparation). The $\Delta \mathrm{p} 85$ inhibits the production of PI 3,4,5 trisphosphate [47] suggesting that this lipid may be a downstream mediator of these effects on glucose transport. Other PI 3-kinases with different specificities have now been discovered. These include a trimeric G-protein-sensitive PI 3-kinase and a PI 3-kinase in which PI is the preferred substrate and which produces PI 3-phosphate instead of PI 3,4,5 trisphosphate [50, 51]. Since these PI 3-kinases do not couple to a regulatory p85 subunit they are unlikely to be important in the acute insulin activation of glucose transport but they may be involved in other aspects of glucose transporter recycling (Section $6 \mathrm{c})$.
An alternative approach, that also implicates PI 3kinase as a signalling intermediate which is critical for the insulin-mediated stimulation of glucose transport, has involved the use of inhibitors of the catalytic activity of the kinase. These include the fungal metabolite, wortmannin and the benzopyran-4-one compound, LY294002. Okada et al. [52] first demonstrated that wortmannin inhibits insulin action on glucose transport in rat adipocytes. A strong correlation has been shown between the ability of wortmannin to inhibit PI 3-kinase and insulin-stimulated GLUT1 and GLUT4 translocation in 3T3-L1 cells. Both PI 3-kinase and glucose transporter translocation are inhibited by wortmannin in the nanomolar concentration range $\left(\mathrm{IC}_{50} \approx 5 \mathrm{nmol} / \mathrm{l}\right)$ in $3 \mathrm{~T} 3-\mathrm{L} 1$ cells [53]. Similar results have been found using LY294002 [54]. Wortmannin also inhibits both PI 3kinase activity and GLUT4 translocation in transfected CHO cells [55]. A disadvantage of the use of PI 3-kinase inhibitors such as wortmannin is that this approach does not discriminate between the different mammalian isoforms of PI 3-kinase which are all inhibited by wortmannin.

More recently the p110 catalytic subunit of PI 3kinase has been transiently transfected in rat adipocytes [56] and 3T3-L1 cells [57] where overexpression leads to increases in basal levels of GLUT1 and GLUT4 at the cell surface by 4-6-fold. These results confirm the importance of PI 3-kinase isoforms in glucose transporter translocation but since the effects observed are on basal transport, more information is required to establish the way in which insulin acutely activates this process.

\section{Role of PI 3-kinase in trafficking kinetics}

a. G eneral effects of PI 3-kinase on membranes and membrane trafficking. The discovery that PI 3-kinase is involved in insulin signalling to glucose transport stimulation has occurred at a time when there has been an accumulating body of evidence that the PI 3-kinase family of proteins is involved in a wide range of membrane trafficking processes. The pinocytic activity, membrane ruffling and actin reorganisation response observed when $\mathrm{KB}$ cells are exposed to insulin has been shown to be due to PI 3-kinase activation [58]. PI 3-kinases have been implicated as key intermediates in the secretory process occurring in platelets, basophil and neutrophil cells [59,60].

This enzyme therefore appears to act at a point of convergence of signalling and trafficking pathways. The general effects of PI 3-kinase on membrane trafficking may provide clues as to the mechanism of action of this enzyme in insulin-stimulated glucose transport. However, a major difference between the majority of the PI 3-kinase dependent membrane processes that have recently been described and the 
glucose stimulation effect is the magnitude of the response. These differences may be dependent on the type of PI 3-kinase involved in each of these processes and the insulin-stimulated PI 3-kinase responsible for the 10-fold increases in glucose transport may involve a highly regulated form of PI 3-kinase.

One of the first indications as to where PI 3-kinases are involved in membrane trafficking processes came from work on the yeast vps34 enzyme. Lack of this enzyme in yeast results in the accumulation of vacuolar hydrolases in prelysosomal and secretory compartments [61, 62]. Wortmannin has been used to show similar PI 3-kinase dependent effects in mammalian cells. In cultured mammalian cells treated with wortmannin lysosomal hydrolases are secreted and the associated cation-independent mannose 6-phosphate receptor (M6PR) and integral membrane glycoproteins such as lpg120 accumulate in prelysosomal compartments $[63,64]$. In the wortmannin-treated cells both the M6PR and lpg120 markers are associated with swollen compartments that appear to be vacuolar. However, the swollen M6PR and $\operatorname{lpg} 120$ compartments are distinct; this suggests that there are multiple sites in prelysosomal sorting where PI 3-kinase is necessary [64]. Normally the M6PR receptor would recycle from sorting endosomes to the trans-Golgi network and so its failure to enter this route suggests that PI 3-kinase is necessary for the exit from the sorting endosomes into a recycling or exocytosis pathway.

The failure of recycling proteins to exit from prelysosomal and recycling endosome compartments contrasts with the lack of effect of wortmannin on entry into the endosome system. Several studies report that wortmannin does not alter the initial endocytosis steps (from the plasma membrane) of transferrin [65] or PDGF receptors [66].

b. Specific involvement of PI 3-kinase in G L UT 4 exocytosis. Photoaffinity tagged GLUT4 has been shown to be continuously recycled both in the presence and absence of insulin. Kinetic studies using a bis-mannose photolabel have suggested that insulin's major effect on GLUT4 trafficking is to stimulate, by 8-10fold, the exocytosis limb of the recycling pathway and a small $(30-50 \%)$ inhibition of endocytosis [6771]. The large (10-fold) effects of insulin on GLUT4 translocation are unusual. Insulin also stimulates the translocation of GLUT1 [67] and transferrin receptors [72] in 3T3-L1 cells by increasing exocytosis by only approximately $2-3$-fold. It seems that GLUT4 may respond more acutely because it is partially sequestered into a separate vesicular system and away from the constitutively recycling endosome pool that is considered to be responsible for trafficking of GLUT1 and transferrin receptors [73]. Wortmannin has been found to completely inhibit the insulin-stimulated exocytosis of both GLUT1 and GLUT4 and interestingly also reduced recycling in basal cells [69]. In no case following wortmannin treatment was there any marked alteration in the initial step in endocytosis. These data are consistent with those observed for wortmannin effects on the recycling of other membrane proteins described in the previous section and a generalisation that could be made is that PI 3-kinase is involved in facilitating the exit from (but not the entry into) recycling endosomes. PI 3kinase activation may enhance exocytosis by increasing the budding of GLUT4 from an intracellularly located tubulo-vesicular system or facilitate the movement or docking of vesicles with the plasma membrane (Fig. 2).

Many of the components involved in vesicle trafficking and docking and fusion are now known. However, the details of the sequence of their participation and the mechanisms by which these processes are regulated are still being debated. It is clear, however, that the NSF (N-ethylmaleimide Sensitive Fusion) protein is central to the whole process and that it interacts with SNAP (Soluble NSF Attachment Proteins) and consequently with SNAP receptors or SNAREs (Fig. 2). Cain et al. [74] made the important observation that vesicle- or v-SNAREs of the synaptobrevin family are present in GLUT4 vesicles. These include synaptobrevin- 2 and cellubrevin but not synaptobrevin-1 [75]. Timmers et al. [75] have also found that these GLUT4 v-SNAREs form a complex with recombinant NSF and $\alpha$-SNAP and that syntaxin- 4 , present in the plasma membrane of rat adipocytes, can also be detected in this complex. Synaxin- 4 and syntaxin- 2 , but not syntaxins $1 \mathrm{a}, 1 \mathrm{~b}$ or 3 , can also be detected in plasma membranes from rat adipocytes but, of these, only syntaxin- 4 can be detected in the NSF complex. Insulin increases the amounts of GLUT4 vesicle synaptobrevin-2 and cellubrevin in the complex. This is partly due to higher levels of these v-SNAREs that are translocated to the plasma membrane from the GLUT4 vesicles but it is also partly due to an increased induction of complex formation. The mechanism by which insulin influences the formation of the fusion complex and how this process is related to upstream kinases and G-proteins has yet to be established. Insulin may remove a fusion clamp that in the basal state blocks the syntaxin-4 participation in fusion. Alternatively, insulin signalling may lead to an enhancement of vesicle v-SNARE participation in complex formation, possibly via the activation of Rab proteins (Fig. 2 and Section $6 \mathrm{c}$ ).

c. Subcellular localisation of G L UT 4 and PI 3-kinase. Immunocytochemistry has been used to try to identify both the trafficking pathway of GLUT4 and the site of PI 3-kinase involvement. Quantitative immunogold analysis on brown adipose tissue has shown GLUT4 localised in many subcellular compartments 


\section{Docking and fusion}
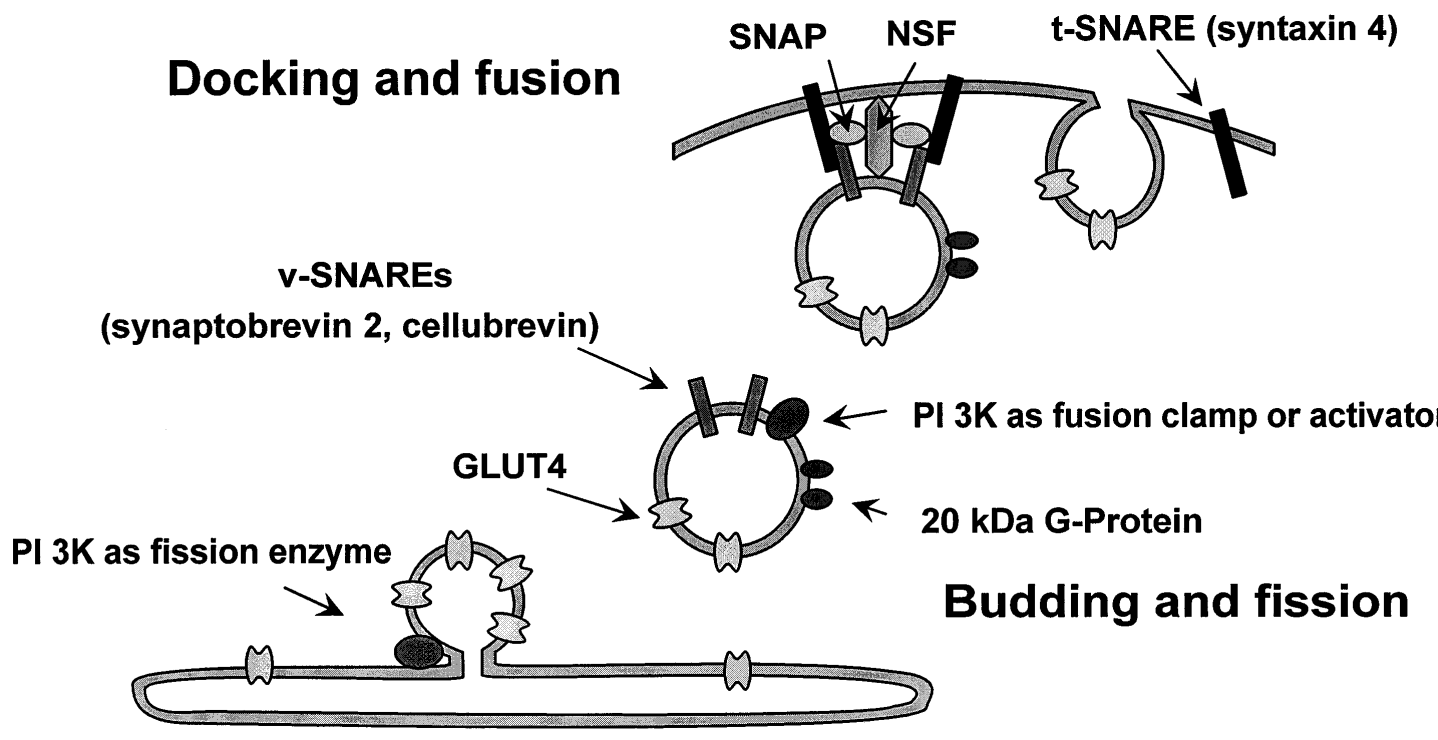

Fig. 2. Regulation of GLUT4 vesicle exocytosis by PI 3-kinase. PI 3-kinase is involved in the subcellular trafficking of membrane proteins at many intracellular locations. It may function to catalyse vesicle fusion in a process that is upstream of Rab proteins which are known to be essential for fusion reactions that facilitate exocytosis. These G-protein mediators may in turn control the assembly of the NSF (N-ethylmaleimide-Sensitive-Fusion) protein and the associated SNAP (Soluble NSF Attachment Protein) and v- and t-SNAREs (SNAP receptors). The v-SNAREs synaptobrevin 2 and cellubrevin are known to be associated with GLUT4 vesicles and these proteins have been demonstrated to form a complex with NSF, SNAP and the t-SNARE, syntaxin 4 of the plasma membrane of insulinstimulated adipose cells. Some evidence suggests that Rab proteins and PI 3-kinase are associated with GLUT4 vesicles but this remains to be more clearly established. Alternatively, PI 3-kinase may act at a vesicle fission step and this could also facilitate exocytosis. This step may also involve small G-proteins, but of the Arf type. These proteins may promote vesicle coat assembly, this being a prerequisite for the fission reaction

including early and recycling endosomes but the basal GLUT4 compartment appears to be distinct [76]. Colocalisation studies carried out in white and brown adipose cells using confocal microscopy suggest that GLUT4 does not co-localise with transferrin receptors or M6PR compartments but does co-localise with VAMP2 in basal cells [77]. Similarly, endosome ablation in 3T3-L1 cells eliminates the transferrin and VAMP3 (cellubrevin) compartments but only partially ablates the VAMP2 and GLUT4 compartments [78]. The effect of wortmannin on GLUT4 immunolocalisation is different depending on whether basal or insulin-stimulated trafficking are perturbed. Wortmannin addition to basal cells traps the GLUT4 in the basal compartment; an inhibition of exit. Wortmannin addition after insulin treatment traps the GLUT4 in a compartment that is associated with vacuoles and in which it co-localises with transferrin receptors, VAMP2 and VAMP3 but not with M6PR or lgp120. It appears that the proteins destined for exit from endosomes accumulate in several subcompartments of the prelysosomal/endosomal system implying that PI 3-kinase is not involved in the sorting steps that separate proteins destined for lysosomes from those destined for return to the plasma membrane. Furthermore, since wortmannin has at least two sites of action on GLUT4 recycling, exit from the basal compartment and exit from the transferrinreceptor/endosome-recycling compartment and has separate cellular sites of action on the M6PR and lgp120 compartments its action may appear to be non-specific. However, the effects it produces are similar in each of the locations suggesting a common mechanism of action at many distinct sites within cell membrane recycling systems.

The common mechanism of PI 3-kinase action is at present unclear and its apparent requirement for exit from a subcellular compartment could imply either an involvement in budding from this donor compartment or heterotypic fusion with the acceptor compartment. Although methods for studying in vesicle budding in a cell-free system are not currently available or being studied in the context of examining PI 3-kinase action, there are several examples of studies leading to evidence that this enzyme is required for membrane fusion (Section $6 \mathrm{c}$ ).

IRS1 associated PI 3-kinase is mainly associated with intracellular low density microsomes isolated from rat adipocytes [79] and 3T3-L1 cells [69]. Interestingly, Kublaoui et al. [80] have shown that there is a strong correlation between insulin action and the endocytosis of autophosphorylated insulin receptor suggesting the possibility of an intracellular membrane site of coupling to IRS1. The intracellular membrane localisation of PI 3-kinase and the evidence that it may catalyse GLUT4 vesicle exocytosis suggest that it may act quite directly in the trafficking 
of GLUT4. Therefore, some further definition of the site of action of PI 3-kinase in the GLUT4 recycling pathway may help define more precisely how it mediates its stimulation. However, attempts to define more precisely the localisation have so far only led to conflicting results. Observations that PDGF [81, 82] and YMXM peptides [83] stimulate the total cellular PI 3-kinase but not the glucose transport activities in 3T3-L1 cells are best explained by invoking a specific insulin-dependent targeting of PI 3-kinase to an intracellular site which is associated with the lowdensity microsome fraction of cells. The specific targeting could be mediated by IRS1 or a similar molecule [69] while PDGF may activate and localise PI 3kinase to the plasma membrane [84]. Del Vechio and Pilch [85] have reported that GLUT4 vesicles isolated from rat adipocytes contain PI 4-kinase but no PI 3-kinase. However, Heller-Harrison et al. [86] have reported that GLUT4 vesicles isolated from 3T3-L1 cells contain PI 3-kinase that is precipitatable by an IRS1 antibody. However, we find that any PI 3kinase that may be associated with GLUT4 vesicles must be a very small (less than $2 \%$ ) fraction of the total cellular PI 3-kinase (Holman et al., unpublished data).

\section{Possible downstream processes}

a. PIP 3 and PIP 3-binding proteins. PI 3-kinase has serine/threonine kinase activity $[87,88]$. This is probably used to regulate the interaction between the p85 and p110 subunits of the enzyme following autophosphorylation of the $\mathrm{p} 85$ by the enzyme activity of the p110 subunits. The physiologically important product of the action of the PI 3-kinase is thought to be PIP3. The PIP3 may interact with downstream signalling molecules and thereby transmit downstream the PI 3-kinase-dependent signalling processes, particularly since PIP3 is not a substrate for known phospholipases. There is evidence that PIP3 can interact with protein kinase B (PKB) [89] and with several protein kinase $\mathrm{C}(\mathrm{PKC})$ isoforms $[90,91]$. There is a parallel translocation of PI 3-kinase and some of the PKC isoforms to the plasma membrane in response to insulin [92, 93]. These serine/threonine kinases may have a role in glucose transport regulation (Section $6 \mathrm{~b}$ ). In addition, other PIP3 receptor proteins have been identified that are implicated in vesicle trafficking processes. These include vesicle associated synaptotagmin, which has calcium and lipid binding domains [94]. GTPase activating proteins that control the GTPase activity of Arf and Arf-like-proteins (Arls) have been isolated from rat brain and shown to be activated by acidic phospholipids [95]. More recently centaurin- $\alpha$, a PIP3 binding protein, has been isolated and cloned from rat brain. Sequence analysis of this protein reveals that it has some homology with
Arf-GAP [96]. Potentially, Rab-GAP proteins may be found that also interact with PIP3.

Several PIP3 binding proteins have been isolated from rat and pig brain cytosol that differ in apparent molecular size and are therefore unrelated or only distantly related to centaurin- $\alpha[97,98]$. Presumably the many downstream events mediated by PI 3-kinases are each catalysed by many separate PIP3 binding proteins and therefore identifying the unique PIP3 receptor involved in regulating glucose transport may be a formidable task.

b. Serine and threonine kinases. Serine and threonine kinase action has been implicated in stimulation of glucose transport mainly because of the action of pharmacological reagents on this process. Among the list of reagents, okadaic acid (a protein phosphatase 1 and 2 a inhibitor) and the PKC inhibitors polymyxin B, staurosporin have been studied most extensively. In most cases it has been unresolved where in the signalling cascade the protein kinase modifiers exert their effects. An effect of okadaic acid on the serine phosphorylation of IRS1 has been suggested leading to an inhibitory effect [99] while a direct stimulatory effect on translocation correlating with the phosphorylation of serine 488 of GLUT4 has been observed [100].

Phorbol-esters which stimulate PKC also lead to stimulations of glucose transport activity [101, 102]. However, these effects are small in comparison with those produced by insulin [103, 104]. The effects appear to be due to 2-3-fold elevations in both GLUT4 and GLUT1 at the cell surface of rat adipose cells [103] and 3T3-L1 cells [104] while insulin produces 10-20-fold elevations of cell surface GLUT4. The effect may be due to stimulation of recruitment from a endosome pool that is common to GLUT1 and GLUT4 but is separate from the specialised pool from which insulin action is able to recruit GLUT4. PKC inhibitory agents such as polymixin B [105] and staurosporin [106] can completely inhibit insulinstimulated glucose transport but high concentrations of these reagents are required and the specificity of the action of these compounds at these concentrations is unknown. Although the involvement of PKC isoforms in the stimulatory effects of insulin seems unlikely, alterations in insulin receptor tyrosine kinase activity mediated by PKC activity in response to elevations in cellular glucose may be an important feedback control of the signalling pathway [107].

The serine/threonine kinases which are downstream of Ras, those of the Map kinase pathway, are unlikely to be involved in mediating the stimulatory effect of insulin on glucose transport. EGF and PDGF are able to mimic insulin's stimulatory effect on Map kinase phosphorylation but do not mimic the stimulation of glucose transport [108, 109]. Birnbaum's group have convincingly shown that the 
activation of the serine kinase Raf (which is downstream of Ras and initiates the Map kinase cascade) does not lead to glucose transport stimulation. Expression of a constituitively active form of Raf in 3T3-L1 cells led to an increase in GLUT1 transcription but did not lead to the translocation of GLUT4 [110].

It has recently been found that $\mathrm{PKB}$ is downstream of PI 3-kinase and inhibitable by wortmannin [111] and activatable by insulin [112]. Insulin activation of this kinase does not appear to be dependent upon its $\mathrm{PH}$ domain but is primarily due to its phosphorylation [113]. Insulin activation of glycogen synthesis involves direct phosphorylation by PKB of glycogen synthase kinase 3 (GSK3) and this occurs downstream of a wortmannin sensitive PI 3-kinase [114]. At present it is unclear whether PKB is so directly involved in regulating glucose transport. In 3T3-L1 cells expressing constitutively active PKB, glucose transport activity is elevated [115]. However, it remains to be established whether an inhibition of PKB blocks insulin stimulation of glucose transport. Activation of p70 S6 kinase appears to involve a divergent pathway from that leading to glucose transport stimulation. This pathway is wortmannin sensitive but is also rapomycin inhibitable, whereas rapomycin has no inhibitory effect on the pathway leading to insulin stimulation of glucose transport [116].

c. G-proteins. In 3T3-L1 cells that have been treated with wortmannin GTP- $\gamma-\mathrm{S}$ is able to produce a stimulation of glucose transport. The effect is smaller than that produced in the absence of the PI 3-kinase inhibitor but this result suggests that G-proteins may be downstream targets of PI 3-kinase in the cascade of intermediates leading to glucose transporter translocation to the plasma membrane [53]. This type of experiment does not distinguish between an involvement of trimeric G-proteins and those of the Ras/ $\mathrm{Rab} /$ Arf superfamily of small ( $\approx 20 \mathrm{kDa}$ ) G-proteins. Indeed, although the small G-protein family seem more likely targets of PI 3-kinase signalling, the trimeric G-protein $\mathrm{G}_{\alpha \mathrm{i}}$ is strongly implicated in the regulation of glucose transporter translocation since a knock-out of this protein in transgenic mice completely blocks the insulin stimulation of GLUT4 translocation [117]. These authors conclude that $G \alpha_{i}$ is an early signalling intermediate above the level of IRS1 phosphorylation. However, when rat adipose cells are treated with insulin and then isoproterenol, which activates $G \alpha_{i}$, they have an attenuated stimulation of glucose transport activity compared with insulin alone. It has been postulated that this effect occurs at a $\mathrm{G} \alpha_{\mathrm{i}}$-dependent GLUT4 vesicle fusion step, a late effect in the cascade linking insulin and glucose transport [118]. Further experiments will presumably clarify the level (or levels) at which $\mathrm{G} \alpha_{\mathrm{i}}$ acts. The GTPase dynamin is important for vesicle budding processes.
Interestingly, dynamin in a complex with Grb2, can be immunoprecipitated with IRS1 in insulin-treated CHO-IR cells [119]. This observation may be significant as it is an additional point of convergence of signalling and trafficking processes. The relationship of this coupling to insulin-stimulated glucose transport has yet to be investigated.

The small G-protein Ras appears not to be involved in normal insulin signalling to glucose transport as the dominant-negative Ras [120] or Ras neutralising antibodies [121] do not inhibit glucose transport under conditions where the activation of the Map kinase cascade is blocked. There are now examples of small G-proteins acting downstream of PI 3kinase in signalling cascades. Rac has been shown to be involved in the membrane ruffling process that is downstream of PI 3-kinase. Modulation of GTP exchange on Rac is postulated to be the means by which its activity is regulated [122]. Insulin stimulated membrane ruffling is inhibited by the $\Delta$-p85 construct [123] and by dominant negative Rac (Kotani et al., unpublished observations). However, Rac does not appear to be involved in the stimulation of glucose transport in 3T3-L1 cells as the introduction of a dominant negative construct of Rac does not significantly inhibit insulin action on this process ([124] and Kotani et al., unpublished observations).

Attractive alternative candidates as the downstream G-proteins in insulin action are the Rab proteins. Although the suggestion that Rab4 is present on GLUT4 vesicles [125] has been disputed, it is clear that perhaps unidentified small G-proteins of this family are present [126]. The nucleotide exchange on $\mathrm{Rab}$ proteins may be altered by dissociation from GDI; there are two isoforms of GDI which differ in their distribution among subcellular fractions of 3T3-L1 cells [127]. A dependence of Rab proteins on PI 3-kinase activity has been suggested from studies of other trafficking proteins. The wortmannin inhibited exit of recycling from prelysosomal compartments is known to depend on Rab 9 [128]. Similarly, in a cell-free endosome fusion assay system addition of constitutively active Rab5 overcame the wortmannin inhibitory effect on fusion [129].

Arf proteins are also implicated in membrane trafficking. They regulate the binding of vesicle coat proteins and adaptins [73] and interestingly their addition (together with phospholipase D and the phosphatidylinositol transfer protein, PITP) to permeabilised cell systems results in restoration of vesicle secretory processes [130]. Their function has been mainly studied in relation to movement between Golgi compartments but more recently a role in endosome fusion [131] and recycling from endosomes to the plasma membrane [132] have been reported. Indeed, an insulin-stimulated translocation of an Arf isoform to the plasma membrane of adipose cells has been reported [133]. Most of the Arf isoforms are 
distributed to intracellular membrane compartments but Arf 6 is present in (but apparently confined to) the plasma membrane of CHO cells [134]. No specific association of Arf proteins with glucose transporter translocation has been demonstrated but investigation of this possibility is warranted, particularly in view of the observation that the PI 3-kinase product PIP3 binds to centaurin- $\alpha$, an Arf-GAP like protein.

\section{Conclusions}

The characterisation of PI3-kinase as a mediator of insulin signalling to glucose transport has been a major advance - it acts as a point of convergence of signalling and membrane trafficking processes. The link between PI 3-kinase and additional molecules that have been suggested as facilitating the complex process of vesicle trafficking is incomplete at present but progress in identifying these links is currently very rapid. As discussed in this review, there is evidence that the PI 3-kinase family of proteins are necessary for many trafficking processes within cells. Additional experimentation is therefore also likely to centre around the questions concerning the specificity of PI 3-kinase effects on glucose transporter translocation. Do specific IRS molecules, PI 3-kinases, phosphatidyinositol binding proteins, serine/threonine kinases and/or Gproteins produce the required specificity?

\section{References}

1. Kasuga M, Fujita-Yamaguchi Y, Blithe D, Kahn CR (1983) Tyrosine-specific protein kinase activity is associated with purified insulin receptor. Proc Natl Acad Sci USA 80:2137-2141

2. Kasuga M, Karlsson FA, Kahn CR (1982) Insulin stimulates the phosphorylation of the 95-000 dalton subunit of its own receptor. Science 215: 185-187

3. Cushman SW, Wardzala LJ (1980) Potential mechanism of insulin action on glucose transport in the isolated rat adipose cell. Apparent translocation of intracellular transport systems to the plasma membrane. J Biol Chem 255: 4758-4762

4. Suzuki K, Kono T (1980) Evidence that insulin causes translocation of glucose transport activity to the plasma membrane from an intracellular storage site. Proc Natl Acad Sci USA 77: 2542-2545

5. Leevers SJ, Marshall CJ (1992) Activation of extracellular signal-regulation kinase, ERK2, by p21Ras oncoprotein. EMBO J 11: 569-574

6. Moodie SA, Willumsen BM, Weber MJ, Wolfman A (1993) Complexes of Ras.GTP with Raf-1 and mitogenactivated protein kinase kinase. Science 260: 1658-1661

7. Zhang X-F, Settleman J, Kyriakis JM et al. (1993) Normal and oncogenic p21 (Ras) proteins bind to the amino-terminal regulatory domain of c-Raf-1. Nature 364: 308-313

8. Sakaue M, Bowtell D, Kasuga M (1995) A dominant-negative mutant of msos1 inhibits insulin-induced Ras activation and reveals Ras-dependent and Ras-independent insulin signaling pathways. Mol Cell Biol 15: 379-388
9. Van Obberghen E, Kasuga M, LeCam A, Itin A, Hedo J-A, Harrison LC (1981) Biosynthetic labeling of the insulin receptor: studies of subunits in cultured human IM-9 lymphocytes. Proc Natl Acad Sci USA 78: 1052-1056

10. Gherzi R, Russell DS, Taylor SI, Rosen OM (1987) Reevaluation of the evidence that an antibody to the insulin receptor is insulin-mimetic without activating the protein tyrosine kinase activity of the receptor. J Biol Chem 262: 16900-16905

11. Chou CK, Dull TJ, Russell DS, Gherzi R, Lebwohl D, Ullrich A, Rosen OM (1987) Human insulin receptors mutated at the ATP-binding site lack protein tyrosine kinase activity and fail to mediate postreceptor effects of insulin. J Biol Chem 262: 1842-1847

12. Yonezawa K, Ando A, Kaburagi Y et al. (1994) Signal transduction pathways from insulin receptors to Ras; analysis by mutant insulin receptors. J Biol Chem 269: 4634-4640

13. Ebina Y, Araki E, Taira M et al. (1987) Replacement of lysine 1030 in the putative ATP-binding region of the insulin receptor abolishes insulin stimulated and antibody stimulated glucose uptake and receptor kinase activity. Proc Natl Acad Sci USA 84: 704-708

14. Quon MJ, Guerre-Millo M, Zarnowski MJ, Butte AJ, Makkalearn E, Cushman SW, Taylor SI (1994b) Tyrosine kinase-deficient mutant human insulin receptor $\left(\mathrm{Met}^{1153}\right.$ Ile) overexpressed in transfected rat adipose cells fail to mediate translocation of epitope-tagged Glut4. Proc Natl Acad Sci USA 91: 5587-5591

15. Ando A, Momomura K, Tobe K et al. (1992) Enhanced insulin-induced mitogenesis and mitogen-activated protein kinase activities in mutant insulin receptors with substitution of $2 \mathrm{COOH}$-terminal tyrosine autophosphorylation sites by phenylalanine. J Biol Chem 267: 1278812796

16. Yamamoto-honda R, Kadowaki T, Momomura K et al. (1993) Normal insulin receptor substrate-1 phosphorylation in autophosphorylation defective truncated insulin receptor; evidence that phosphorylation of substrates might be sufficient for certain biological effects evoked by insulin. J Biol Chem 268: 16859-16865

17. Maegawa H, McClain DA, Freidenberg G et al. (1988) Properties of a human insulin receptor with a $\mathrm{COOH}-$ terminal truncation. Truncated receptors have normal kinase activity but are defective in signalling metabolic effects. J Biol Chem 263: 8912-8917

18. Mosthaf L, Berti L, Kellerer M et al. (1995) C-terminus or juxtramembrane deletions in the insulin receptor do not affect the glucose dependent inhibition of the tyrosine kinase activity. Eur J Biochem 227: 787-791

19. White MF, Livingston JN, Backer JM, Lauris V, Dull TJ, Ullrich A, Kahn CR (1988) Mutation of the insulin receptor at tyrosine 960 inhibits signal transmission but does not affect its tyrosine kinase activity. Cell 54: 641-649

20. Sun XJ, Rothenberg P, Kahn CR et al. (1991) Structure of the insulin receptor substrate IRS-1 defines a unique signal transduction protein. Nature 352: 73-77

21. Keller SR, Aebersold R, Garner CW, Lienhard GE (1993) The insulin elicited $160 \mathrm{kDa}$ phosphotyrosine protein in mouse adipocytes is an insulin receptor substrate-1 - identification by cloning. Biochim Biophys Acta 1172: 323-326

22. Yenush L, Makati KJ, Smith-Hall J, Ishibashi O, Myers MG Jr, White MF (1996) The pleckstrin homology domain is the principle link between the insulin receptor and IRS1. J Biol Chem 271: 24300-24306

23. O’Neill TJ, Craparo A, Gustafson TA (1994) Characterization of an interaction between insulin receptor 
substrate-1 and insulin receptor by using the 2-hybrid system. Mol Cell Biol 14: 6433-6442

24. Izumi T, White MF, Kadowaki T, Takaku F, Akanuma Y, Kasuga M (1987) Insulin-like growth factor-1 rapidly stimulates tyrosine phosphorylation of a Mr 185,000 protein in intact cells. J Biol Chem 262: 1282-1287

25. Araki E, Lipes MA, Patti ME, Bruning JC, Haag B, Johnson RS, Kahn CR (1994) Alternative pathways of insulin signaling in mice with targeted disruption of the IRS-1 gene. Nature 372: 186-190

26. Tamemoto H, Kadowaki T, Tobe K et al. (1994) Insulin resistance and growth retardation in mice lacking insulin receptor substrate-1. Nature 372: 182-186

27. Sun XJ, Wang LM, Zhang YT et al. (1995) Role of IRS-2 in insulin and cytokine signaling. Nature 337: 173-77

28. Quon MJ, Butte AJ, Zarnowski MJ, Sesti G, Cushman SW, Taylor SI (1994a) Insulin receptor substrate-1 mediates the stimulatory effect of insulin on Glut 4 translocation in transfected rat adipose cells. J Biol Chem 269: 2792027924

29. Morris AJ, Martin SS, Haruta Tet al. (1996) Evidence for an insulin receptor substrate-1 independent signalling pathway that mediates insulin-responsive glucose transporter (GLUT4) translocation. Proc Natl Acad Sci USA 93: 8401-8406

30. Lavan BE, Kuhne MR, Garner CW, Anderson D, Reedijk M, Pawson T, Lienhard GE (1992) Dephosphorylation of insulin receptor substrate-1 by tyrosine phosphatase PTP2C. J Biol Chem 267: 11631-11636

31. Noguchi T, Matozaki T, Horita K, Fujioka Y, Kasuga M (1994) Role of SH-PTP2, a protein tyrosine phosphatase with src homology-2 domains, in insulin-stimulated Ras activation. Mol Cell Biol 14: 6674-6682

32. Hausdorff S, Bennet A, Neel B, Birnbaum M (1995) Different signalling roles of SH-PTP2 in insulin-induced GLUT1 expression and GLUT4 translocation. J Biol Chem 270: 12965-12968

33. Whitman M, Downes CP, Keeler M, Keller T, Cantley L (1988) Type-1 phosphatidyinositol kinase makes a novel inositol phospholipid, phosphatidylinositol-3-phosphate. Nature 332: 644-646

34. Auger KR, Serunian LA, Soltoff SP, Libby P, Cantley LC (1989) PDGF-dependent tyrosine phosphorylation stimulates production of novel polyphosphoinositides in intact cells. Cell 57: 167-175

35. Otsu M, Hiles T, Gout I et al. (1991) Characterization of 2 $85 \mathrm{kD}$ proteins that associate with receptor tyrosine kinases, middle-t/pp60C-src complexes, and PI 3-kinase. Cell 65: $91-104$

36. Skolnik EY, Margolis B, Mohammadi M et al. (1991) Cloning of PI 3 kinase associated p85 utilizing a novel method for expression cloning of target proteins for receptor tyrosine kinases. Cell 65: 83-90

37. Escobedo JA, Navankasattusas S, Kavanaugh WM, Milfay D, FriedVA, Williams LT (1991) cDNA cloning of a novel $85 \mathrm{kD}$ protein that has $\mathrm{SH} 2$ domains and regulates binding of PI 3-kinase to the PDGF-beta receptor. Cell 65: 75-82

38. Hiles ID, Otsu M, Volinia S et al. (1992) Phosphatidylinositol 3-kinase - structure and expression of the $110 \mathrm{kD}$ catalytic subunit. Cell 70: 419-429

39. Hu P, Mondino P, Skolnik EY, Schlessinger J (1993) Cloning of a novel ubiquitously expressed human phosphatidylinositol 3-kinase and identification of its binding site on p85. Mol Cell Biol 13: 7677-7688

40. Endemann G, Yonezawa K, Roth RA (1990) Phosphatidylinositol kinase or an associated protein is a substrate for the insulin receptor tyrosine kinase. J Biol Chem 265: 396-400

41. Ruderman N, Kapeller R, White MF, Cantley LC (1990) Activation of phosphatidylinositol 3-kinase by insulin. Proc Natl Acad Sci USA 87: 1411-1415

42. Vanhorn DJ, Myers MG, Backer JM (1994) Direct activation of the phosphatidylinositol 3-kinase by the insulin receptor. J Biol Chem 269: 29-32

43. Yonezawa K, Yokono K, Shii K et al. (1992) In vitro association of phosphatidylinositol 3-kinase activity with the activated insulin-receptor tyrosine kinase. J Biol Chem 267: 440-446

44. Backer JM, Myers M Jr, Shoelson SE et al. (1992) Phosphatidylinositol 3-kinase is activated by association with IRS-1 during insulin stimulation EMBO J 9: 34693479

45. Yonezawa K, Ueda H, Hara K et al. (1992) Insulin dependent formation of a complex containing an $85 \mathrm{kDa}$ subunit of phosphatidylinositol 3-kinase and tyrosine phosphorylated insulin receptor substrate-1. J Biol Chem 267: 25958-25965

46. Hara K, Yonezawa K, Sakaue H et al. (1993) Insulin induced complex formation of PI 3-kinase activity with IRS- 1 is required for the increase in PI $(3,4,5) \mathrm{P} 3$ and PI $(3,4) \mathrm{P} 2$ and the stimulation of glucose transport. Diabetes 42:[Suppl 1]:143A (Abstract)

47. Hara K, Yonezawa K, Sakaue H et al. (1994) Phosphatidylinositol 3-kinase activity is required for insulin-stimulated glucose transport but not Ras activation in $\mathrm{CHO}$ cells. Proc Natl Acad Sci USA 91: 7415-7419

48. Dhand R, Hara K, Hiles I et al. (1994 a) PI 3-kinase structural and functional analysis of intersubunit interactions. EMBO J 13: 511-521

49. Kotani K, Hara K, Kotani K, Yonezawa K, Kasuga M (1995) Phosphoinositide 3-kinase as an upstream regulator of the small GTP-binding protein Rac in the insulin signaling of membrane ruffling. Biochem Biophys Res Comm 208: 985-990

50. Stoyanov B, Volinia S, Hanck T et al. (1995) Cloning and characterization of a G-protein activated human phosphatidylinositide 3-kinase. Science 269: 690-693

51. Volinia S, Dhand R, Vanhaesebroeck B et al. (1995) Human phosphatidylinositol 3-kinase complex related to the yeast vps34p-vps15p protein sorting system. EMBO J 14: $101-110$

52. Okada T, Kawano T, Sakakibara T, Hazeki O, Ui M (1994) Essential role of phosphatidylinositol 3-kinase in insulininduced glucose transport and anti-lipolysis in rat adipocytes - studies with a selective inhibitor wortmannin. J Biol Chem 269: 3568-3573

53. Clarke JF, Young PW, Yonezawa K, Kasuga M, Holman GD (1994) Inhibition of the translocation of GLUT1 and GLUT4 in 3T3-L1 cells by the PI 3-kinase inhibitor, wortmannin. Biochem J 300: 631-635

54. Cheatham B, Vlahos CJ, Cheatham L, Wang L, Blenis J, Kahn CR (1994) Phosphatidylinositol 3-kinase is required for insulin stimulation of pp70 S6 kinase, DNA synthesis, and glucose transporter translocation. Mol Cell Biol 14: 4902-4911

55. Kanai F, Ito K, Todaka M et al. (1993) Insulin-stimulated GLUT4 translocation is relevant to the phosphorylation of IRS1 and activity of PI 3-kinase. Biochem Biophys Res Comm 195: 762-768

56. Tanti JF, Gremeaux T, Grillo S et al. (1996) Overexpression of a constitutively active form of phosphatidylinositol 3-kinase is sufficient to promote GLUT4 translocation in adipocytes. J Biol Chem 41: 25227-25232 
57. Katagiri H, Asano T, Ishihara H et al. (1996) Overexpression of catalytic subunit p110-alpha of phosphatidylinositol 3-kinase increases glucose transport activity and translocation of glucose transporters in 3T3-L1 adipocytes. J Biol Chem 271: 16987-16990

58. Kotani K, Yonezawa K, Hara K et al. (1994) Involvement of phosphoinositide 3-kinase in insulin induced or IGF-1 induced membrane ruffling. EMBO J 13: 2313-2321

59. YatomiY, Hazeki O, Kume S, Ui M (1992) Suppression by wortmannin of platelet responses to stimuli due to inhibition of pleckstrin phosphorylation. Biochem J 285: 7457517

60. Yano H, Nakanishi S, Kimura K et al. (1993) Inhibition of histamine secretion by wortmannin through blockage of phosphatidylinositol 3-kinase in RBL-2H3 cells. J Biol Chem 268: 25846-25856

61. Schu PV, Takegawa K, Fry MJ, Stack JH, Waterfield MD, Emr SD (1993) Phosphatidylinositol 3-kinase encoded by yeast vps34 gene essential for protein sorting. Science 260: 88-91

62. Stack JH, Herman PK, Schu PV, Emr SD (1993) A membrane-associated complex containing the Vps15 protein kinase and the yeast Vps34 PI 3-kinase is essential for protein sorting to the yeast lysosome-like vacuole. EMBO J 12: $2195-2204$

63. Brown WJ, Dewald DB, Emr SD, Plutner H, Balch WE (1995) Role for phosphatidylinostol 3-kinase in the sorting and transport of newly synthesized lysosomal enzymes in mammalian cells. J Cell Biol 130: 781-796

64. Reaves BJ, Bright NA, Mullock BM, Luzio JP (1996) The effect of wortmannin on the localisation of lysosomal type 1 intergral membrane glycoproteins suggests a role for phosphoinositide 3-kinase activity in regulating membrane traffic late in the endocytic pathway. J Cell Science 109: 749-762

65. Shepherd PR, Soos M A, Siddle K (1995) Inhibitors of phosphoinositide 3-kinase block exocytosis but not endocytosis of transferrin receptors in 3T3-L1 adipocytes. Biochim Biophys Res Comm 211: 535-539

66. Joly M, Kazlauskas A, Corvera S (1994) Phosphatidylinositol 3-kinase activity is required at a post-endosomal step in platelet-derived growth factor receptor trafficking. J Biol Chem 270: 13225-13230

67. Yang J, Holman GD (1993) Comparison of GLUT4 and GLUT1 subcellular trafficking in basal and insulin-stimulated 3T3-L1 cells. J Biol Chem 268: 4600-4603

68. Satoh S, Nishimura H, Clark AE et al. (1993) Use of bismannose photolabel to elucidate insulin-regulated GLUT4 subcellular trafficking kinetics in rat adipose cells: evidence that exocytosis is critical site of hormone action. J Biol Chem 269: 17820-17829

69. Yang J, Clarke JF, Ester CJ, Young PW, Kasuga M, Holman GD (1996) Phosphatidylinositol-3-kinase acts at an intracellular membrane site to enhance GLUT4 exocytosis in 3T3-L1 cells. Biochem J 313: 125-131

70. Czech MP, Buxton JM (1993) Insulin action on the internalization of the GLUT4 glucose transporter in isolated rat adipocytes. J Biol Chem 268: 9187-9191

71. Jhun BH, Rampal H, Liu M, Lachaal M, Jung CY (1992) Effects of insulin on steady-state kinetics of GLUT4 subcellular distribution in rat adipocytes - evidence for constitutive GLUT4 recycling. J Biol Chem 267: 1771017715

72. Tanner LI, Lienhard GE (1987) Insulin elicits a redistribution of transferrin receptors in 3T3-L1 adipocytes through an increase in the rate constant for receptor externalization. J Biol Chem 262: 8975-8980
73. Holman GD, Lo Leggio L, Cushman SW (1994) Multiple pool membrane protein trafficking: application to insulin stimulated glucose transporter recycling. J Biol Chem 269: 17516-17524

74. Cain CC, Trimble WS, Lienhard GE (1992) Members of the VAMP family of synaptic vesicle proteins are components of glucose transporter-containing vesicles from rat adipocytes. J Biol Chem 267: 11681-11684

75. Timmers KI, Clark AE, Omatsu-Kanbe M, Whiteheart SW, Bennett MK, Holman GD, Cushman SW (1996) Identification of SNAP receptors in rat adipose cell membrane fractions and in SNARE complexes co-immunoprecipitated with epitope-tagged NSF. Biochem $J$ in press

76. Slot JW, Gueze HJ, Gigengack S, Lienhard GE, James DE (1991) Immunolocalization of the insulin regulatable glucose transporter in brown adipose tissue of the rat. J Cell Biol 113: 123-135

77. Malide D, Dwyer NK, Blanchette-Mackie EJ, Cushman SW (1996) Dissection of the insulin responsive GLUT4 subcellular trafficking pathway in rat adipose cells using the PI 3kinase inhibitor wortmannin: a confocal microscopy approach. Exp Clin Endocrinol Diabetes 104:[Suppl 2] 39

78. Livingstone C, James DE, Rice JE, Hanpeter D, Gould GW (1996) Compartment ablation analysis of the insulin-responsive glucose transporter (GLUT4) in 3T3-L1 cells. Biochem J 315: 487-495

79. Kelly KL, Ruderman NB, Chen KS (1992) Phosphatidylinositol 3-kinase in isolated rat adipocytes. Activation by insulin and subcellular distribution. J Biol Chem 267: 3423-3428

80. Kublaoui B, Lee J, Pilch PF (1995) Dynamics of signaling during insulin-stimulated endocytosis of its receptor in adipocytes. J Biol Chem 270: 59-65

81. Isakoff SJ, Taha C, Rose E, Marcusohn J, Klip A, Skolnik Y (1995) The inability of phosphatidylinositol 3-kinase activation to stimulate GLUT4 translocation indicates additional signaling pathways are required for insulin stimulated glucose uptake. Proc Natl Acad Sci USA 92: 1024710251

82. Wiese RJ, Mastick CC, Lazar DF, Saltiel AR (1995) Activation of mitogen-activated protein kinase and phosphatidylinositol 3-kinase is not sufficient for the hormonal stimulation of glucose transport, lipogenesis, or glycogen synthesis in 3T3-L1 adipocytes. J Biol Chem 270: 3442-3446

83. Herbst JJ, Andrews GC, Cortillo LG, Singleton DH, Genereux PE, Gibbs EM, Lienhard GE (1995) Effect of the activation of phosphatidylinositol 3-kinase by a thiophosphotyrosine peptide on glucose transport in 3T3-L1 adipocytes. J Biol Chem 270: 26000-26005

84. Nave BT, Haigh RJ, Hayward AC, Siddle K, Shepherd PR (1996) Compartment specific regulation of phosphoinositide 3-kinase by platelet derived growth factor and insulin in 3T3-L1 adipocytes. Biochem J 318: 55-60

85. Del Vecchio RL, Pilch PF (1991) Phosphatidylinositol 4kinase is a component of glucose transporter (GLUT4)containing vesicles. J Biol Chem 266: 13278-13283

86. Heller-Harrison RA, Morin M, Guilherme A, Czech MP (1996) Insulin mediated targeting of phosphatidylinositol 3-kinase to GLUT4-containing vesicles. J Biol Chem 271: 10200-10204

87. Dhand R, Hiles I, Panayotou G et al. (1994) PI 3-kinase is a dual-specificity enzyme - autoregulation by an intrinsic protein serine kinase activity. EMBO J 13: 522-533

88. Tanti JF, Gremeaux T, Van Obberghen E, LeMarchardBrustel Y (1994) Insulin receptor substrate-1 is phosphorylated by the serine kinase activity of phosphatidylinositol 3-kinase. Biochem J 304: 17-21 
89. Franke TF, Yang S-I, Chan TO, Datta K, Kazlauskas A, Morrison DK, Kaplan D, Tsichlis PN (1995) The protein kinase encoded by the Akt proto-oncogene is a target of the PDGF-activated phosphatidylinositol 3-kinase cell. 81: 727-736

90. Nakanishi H, Brewer KA, Exton JH (1993) Activation of the zeta isozyme of protein kinase $\mathrm{C}$ by phosphatidylinositol 3,4,5-trisphosphate. J Biol Chem 268: 13-18

91. Toker A, Meyer M, Reddy KK et al. (1994) Activation of protein kinase $\mathrm{C}$ family members by the novel phosphoinositides PtdIns-3,4-P2 and PtdIns-3,4,5-P3. J Biol Chem 269: 32358-32367

92. Mosthaf L, Kellerer M, Muhlhofer A, Mushack J, Seffer E, Haring HU (1996) Insulin leads to a parallel translocation of PI 3-kinase and protein kinase C-zeta. Exp Clin Endocrinol Diab 104: 19-24

93. Yamada K, Avignon A, Standaert ML, Cooper DR, Spencer B, Farase RV (1995) Effects of insulin on the translocation of protein kinase $\mathrm{C}$ theta and other protein kinase $\mathrm{C}$ isoforms in rat skeletal muscle. Biochem J 308: 177-180

94. Fukuda M, Kojima T, Mikoshiba K (1996) Phospholipid composition dependence of $\mathrm{Ca}^{++}$dependent phospholipid binding to the $\mathrm{C} 2 \mathrm{~A}$ domain of synaptotagmin IV. J Biol Chem 271: 8430-8434

95. Rondazzo PA, Kahn RA (1994) GTP hydrolysis by ADPribosylation factor is dependent on both an ADP-ribosylation factor GTPase-activating protein and acidic phospholipids. J Biol Chem 269: 10758-10763

96. Hammonds-Odie LP, Jackson TR, Profit AA, Blader IJ, Turck CW, Prestwich GD, Theibert AB (1996) Identification and cloning of centaurin- $\alpha$; a novel phosphatidylinositol 3,4,5-trisphosphate-binding protein from rat brain. J Biol Chem 271: 18859-18868

97. Ogawa W, Roth RA (1994) Characterization of a protein which binds phosphatidylinositol 3,4,5-trisphosphate and 4,5-bisphosphate. Biochim Biophys Acta 1224: 533-540

98. Stricker R, Kalbacher H, Lottspeich F, Reiser G (1995) Characterization of a high affinity Ins-P-4 (inositol 1,3,4,5-tetrakisphosphate) receptor from brain by an antipeptide antiserum. FEBS Lett 370: 236-240

99. Tanti JF, Gremeaux T, Van Obberghen E, Le MarchandBrustel Y (1994) Serine/threonine phosphorylation of insulin receptor substrate-1 modifies insulin receptor signaling. J Biol Chem 269: 6051-6057

100. Lawrence JCJ, Hiken JF, James DE (1990) Stimulation of glucose transport and glucose transporter phosphorylation by okadaic acid in rat adipocytes. J Biol Chem 265: 19768-19776

101. Kirsch D, Obermaier B, Haring HU (1985) Phorbolesters enhance D-glucose transport but inhibit insulin stimulation of D-glucose transport and insulin binding in isolated rat adipocytes. Biochem Biophs Res Comm 128: 824832

102. Haring HU (1991) The insulin receptor - signaling mechanism and contribution to the pathogenesis of insulin resistance. Diabetologia 34: 848-861

103. Holman GD, Kozka IJ, Clark AE et al. (1990) Cell-surface labeling of glucose transporter isoform GLUT4 by bismannose photolabel: correlation with stimulation of glucose transport in rat adipose cells by insulin and phorbol ester. J Biol Chem 265:18172-18179

104. Gibbs EM, Calderhead DM, Holman GD Gould GW (1991) Phorbol ester only partially mimics the effects of insulin on glucose transport and glucose-transporter distribution in 3T3-L1 adipocytes. Biochem J 275: 145-150

105. Cormont M, Gremeaux T, Tanti JF, Van Obberghen E, Le Marchand-Brustel Y (1992) Polymyxin B inhibits insulin induced glucose transporter and IGF-II receptor translocation in isolated adipocytes. Eur J Biochem 207: 185-193

106. Nishimura H, Simpson IA (1994) Staurosporin inhibits phorbol 12-myristate 13-acetate-stimulated and insulinstimulated translocation of GLUT1 and GLUT4 glucose transporters in rat adipose cells. Biochem J 302: 271-277

107. Haring HU, Kellerer M, Mosthaf L (1994) Modulation of insulin signaling in non-insulin-dependent-diabetes-mellitus - significance of altered receptor isoform patterns and mechanism of glucose induced modulation. Hormone Res 41: 87-92

108. Robinson LJ, Razzack ZF, Lawrence JC, James DE (1993) Mitogen activated protein kinase activation is not sufficient for stimulation of glucose transport or glycogen synthase in 3T3-L1 adipocytes. J Biol Chem 268: 26422-26427

109. Gould GW, Merral NW, Martin S et al. (1994) Growth factor induced stimulation of hexose transport in 3T3-L1 adipocytes. Evidence that insulin-induced translocation of GLUT4 is independent of activation of MAP kinase. Cell Signal 6: 313-320

110. Fingar DC, Birnbaum MJ (1994) A role for raf-1 in the divergent signaling pathways mediating insulin-stimulated glucose transport. J Biol Chem 269: 10127-10132

111. Burgering M, Coffer P (1995) Protein kinase N (c-Akt) in phosphatidylinositol-3-OH kinase signal transduction $\mathrm{Na}-$ ture 376: 599-602

112. Kohn AD, Kovacina K, Roth RA (1995) Insulin stimulates the kinase activity of RAC-PK, a pleckstrin homology domain containing ser/thr kinase. EMBO J 14: 4288-4295

113. Kohn AD, Takeuchi F, Roth RA (1996) Akt, a pleckstrin homology domain containing kinase, is activated primarily by phosphorylation. J Biol Chem 271: 21920-21926

114. Cross DAE, Alessi DR, Cohen P, Andjelkovich M, Hemmings BA (1995) Inhibition of glycogen synthase kinase3 by insulin mediated by protein kinase B. Nature 378 : 785-789

115. Kohn AD, Summers SA, Birnbaum MJ, Roth RA (1996) Expression of a constitutively active Akt ser/thr kinase in 3T3-L1 adipocytes stimulates glucose transport and glucose transporter-4 translocation. J Biol Chem 271: 3137231378

116. Fingar DC, Hausdorff SF, Blenis J, Birnbaum MJ (1993) Dissociation of pp70 ribosomal protein S6 kinase from insulin-stimulated glucose transport in 3T3-L1 cells. J Biol Chem 268: 3005-3008

117. Moxham CM, Malbon CC (1996) Insulin action impaired by deficiency of the G-protein subunit $\mathrm{G}\left(\mathrm{I} \alpha_{2}\right)$. Nature 379: 840-844

118. Vannucci SJ, Nishimura H, Satoh S, Cushman SW, Holman GD, Simpson IA (1992) Changes in cell-surface accessibility of GLUT4 glucose transporter: effect of insulin, isoproterenol and adenosine. Biochem J 288: 325-330

119. Ando A, Yonezawa K, Gout I et al. (1994) A complex of Grb2 dynamin binds to tyrosine phosphorylated insulin receptor substrate-1 after insulin treatment. EMBO J 13: 3033-3038

120. Quon M, Chen H, Ing B et al. (1995) Roles of 1-phosphatidylinositol 3-kinase and Ras in regulating translocation of GLUT4 in transfected rat adipose cells. Mol Cell Biol 15: 5403-5411

121. Manchester J, Kong XM, Lowry OH, Lawrence JC (1994) Ras signaling in the activation of glucose transport by insulin. Proc Natl Acad Sci USA 91: 4644-4648

122. Bokoch GM, Bohl BP, Chuang TH (1994) Guanine nucleotide exchange regulates membrane translocation of Rac/ Rho GTP-binding proteins. J Biol Chem 269: 3167431679 
123. Kotani K, Carozzi AJ, Sakaue H et al. (1995) Requirement for phosphoinositide 3-kinase in insulin stimulated Glut4 translocation in 3T3-L1 adipocytes. Biochem Biophys Res Comm 209: 343-348

124. Marcusohn J, Isakoff SJ, Rose E, Symons M, Skolnik EY (1995) The GTP-binding protein Rac does not couple PI 3-kinase to insulin-stimulated glucose transport. Current Biology 5: 1296-1302

125. Cormont M, Tanti J-F, Zahraoui A, Van Obberghen E, Tavitian A, Le Marchand-Brustel Y (1993) Insulin and okadaic acid induce Rab4 redistribution in adipocytes. J Biol Chem 268: 19491-19497

126. Uphues I, Kolter T, Goud B, Eckel J (1994) Insulin-induced translocation of the glucose transporter GLUT4 in cardiac muscle. Studies on the role of small molecular mass GTP-binding proteins. Biochem J 301: 177-182

127. Shisheva A, Buxton J, Czech MP (1994) Differential intracellular localizations of GDP dissociation inhibitor isoforms - insulin dependent redistribution of GDP dissociation inhibitor-2 in 3T3-L1 adipocytes. J Biol Chem 269: 23865-23868

128. Riederer MA, Soldati T, Shapiro AD, Lin J, Pfeffer SR (1994) Lysosome biosynthesis requires Rab 9 function and receptor recycling from endosomes to the trans-Golgi network. J Cell Biol 125: 573-582
129. Li G, D'Souza-Schorey C, Barbiere MA, Roberts RL, Klippel A, Williams LT, Stahl PD (1995) Evidence for phosphatidylinositol 3-kinase as a regulator of endocytosis via activation of Rab5. Proc Natl Acad Sci USA 92: 10207-10211

130. Fensome A, Cunningham E, Prosser S, Tan SK, Swigart P, Thomas G, Hsuan J, Cockcroft S (1996) Arf and PITP restore GTP- $\gamma$-S stimulated protein secretion from cytosol depleted HL-60 cells by promoting PIP2 synthesis. Current Biol 6: 730-738

131. Lenhard JM, Kahn RA, Stahl PD (1992) Evidence for ADP-ribosylation factor (Arf) as a regulator of in vitro endosome-endosome fusion. J Biol Chem 267: 1304713052

132. Whitney JA, Gomez M, Sheff D, Kreiss TE, Mellman I (1995) Cytoplasmic coat proteins involved in endosome function. Cell 83: 703-713

133. Karnam PR, Standaert ML, Galloway L, Farese RV (1996) Insulin rapidly translocates small G-proteins, rho and arf, to the plasma membrane in rat adipocytes. Diabetes 45:[Supp 2] 575

134. Cavenagh MM, Whitney JA, Carroll K et al. (1996) Intracellular distribution of Arf proteins in mammalian cells; Arf 6 is uniquely localized to the plasma membrane. J Biol Chem 271: 1767-21774 